\title{
Subcellular localization, abundance and stability of chitin synthetases 1 and 2 from Saccharomyces cerevisiae
}

\author{
Carlos A. Leal-Morales, ${ }^{1}$ Charles E. Bracker ${ }^{2}$ and Salomon Bartnicki- \\ Garcia $^{3}$
}

Author for correspondence: Salomon Bartnicki-Garcia. Tel: +1 909787 4135. Fax: +1 9097874294

\footnotetext{
1 Instituto de Investigación en Biología Experimental, Facultad de Química Universidad de Guanajuato, Guanajuato, Mexico

2 Department of Botany and Plant Pathology, Purdue University, West Lafayette, IN 47907, USA

3 Department of Plant Pathology, University of California, Riverside, CA 92521, USA
}

\begin{abstract}
The existence of more than one chitin synthetase in fungal cells poses the question of whether these enzymes have similar or different localization. The subcellular distribution of chitin synthetases 1 and 2 (Chs1 and Chs2) was determined in cell-free extracts of Saccharomyces cerevisiae fractionated by sucrose density gradient sedimentation. Chs 1 was examined in two strains: ATCC 26109, a wild-type strain, and D3C (MAT $\alpha$ ura3-52). Chs2 was investigated in a strain (D3B) freed of Chs1 by gene disruption (MATa his4 ura3-52 chs1:: URA3). A prolonged, strong centrifugation $(20 \mathrm{~h}$ at $265000 \mathrm{~g})$ was necessary to cleanly resolve two major populations of chitin synthetase particles: chitosomes (a population of microvesicles of low buoyant density, $d=1.15 \mathrm{~g} \mathrm{ml}^{-1}$ ) and plasma membrane (a population of vesicles of high buoyant density, $d=1.21 \mathrm{~g} \mathrm{ml}^{-1}$ ). Chs1 and Chs2 were both present in chitosomes and plasma membrane, but the relative distribution of each chitin synthetase in these two membranous populations varied. Chs2 was much less abundant than Chs1 and required $\mathrm{Co}^{2+}$ rather than $\mathrm{Mg}^{2+}$ as a cofactor. A salient finding was the high sensitivity of chitosomal Chs2 to high centrifugal forces. The subcellular distribution of $1,3-\beta$-glucan synthetase was the same in the three strains studied, i.e. unaffected by the presence or absence of Chs 1 . Culture conditions affected the profiles of chitin and glucan synthetases: the relative abundance of Chs 1 in chitosomes or plasma membrane was quite different in cells grown on two different media but the buoyant density was not affected; in contrast, there was shift in the buoyant density of the two peaks of 1,3- $\beta$-glucan synthetase. We concluded that the subcellular localization of Chs1 and Chs2 remains the same despite genetic and other differences in the properties of these enzymes. We confirmed that 1,3- $\beta$-glucan synthetase and chitin synthetase exhibit a partially different subcellular distribution - an indication that these two enzymes are mobilized through different secretory pathways.
\end{abstract}

Keywords: Chitin synthetases Chs1 and Chs2, chitosomes, 1,3- $\beta$-glucan synthetase, plasma membrane, Saccharomyces cerevisiae

\section{INTRODUCTION}

Studies on chitin synthetase (EC 2.4.1.16) in different fungi have identified two major subcellular locations: chitosomes (Bracker et al., 1976; Bartnicki-Garcia et al.,

Abbreviations: Chs1, chitin synthetase 1; Chs2, chitin synthetase 2; UDP-GICNAC, uridine diphosphate $\mathrm{N}$-acetyl-D-glucosamine; YPG, yeast extract/peptone/glucose medium. YNBG, yeast nitrogen base/glucose medium.
1978; Hanseler et al., 1983; Flores Martinez \& Schwencke, 1988; Gozalbo et al., 1992) and plasma membrane (Duran et al., 1975; Jan 1974; Dalley \& Sonneborn, 1982). Initially, in Saccharomyces cerevisiae Cabib and co-workers showed a plasma membrane localization for the enzyme later identified as chitin synthetase 1 (Chs1) (Cabib \& Farkas, 1971 ; Duran et al., 1975; Cabib et al., 1983). With improved methods for separating membranous organelles by density gradient sedimentation, we demonstrated that Chs1 was present in both chitosomes and plasma mem- 
brane of growing cells of $S$. cerevisiae (Leal-Morales et al., 1988). A similar dual location was observed in protoplast: of S. cerevisiae (Flores Martinez \& Schwencke, 1988).

Molecular genetic studies on chitin synthetase from $S$. cerevisiae (Bulawa et al., 1986; Sburlati \& Cabib, 1986 , Bulawa \& Osmond, 1990; see review by Bulawa, 1993; revealed several genes coding for three chitin synthetases (Chs1, Chs2, and Chs3). Gene disruption experiments suggested that each enzyme governs a different function (Bulawa et al., 1986; Silverman et al., 1988; Bulawa \& Osmond, 1990; Shaw et al., 1991; Bowen et al., 1992). It has been proposed that Chs1 has a secondary role as a repair enzyme, while Chs 2 is mainly responsible for septum formation (Cabib et al., 1989) and Chs3 is thought to be the main enzyme involved in chitin synthesis in yeast (lateral walls and spore wall chitosan) (Shaw et al., 1991; Bulawa, 1993).

To determine whether two chitin synthetases coded by different genes have the same subcellular distribution, we examined the distribution of Chs 2 in fractionated cell-free extracts to compare it with our previous findings on Chs1. Since Chs1 is the dominant chitin synthetase in wildtype cells, it was necessary to use a yeast strain (D3B) lacking Chs1, through disruption of its CHS1 gene (chs1::UR A3), to determine the localization and properties of Chs2. Possible interference by Chs 3 was deemed unlikely since it is present only in small amounts and does not respond to activating protease (Shaw et al., 1991). We found that Chs 2 was also distributed in two major subcellular fractions with different buoyant densities and sedimentation velocities.

\section{METHODS}

Strains. For studies on Chs2 we used the D3B strain of Saccharomyces cerevisiae freed of Chs1 by gene disruption (MATa bis4 ura3-52 cbs 1:: UR $A 3$ ) (Sburlati \& Cabib, 1986). For studies on Chs1, two strains of $S$. cerevisiae were used: ATCC 26109, a wild-type strain we previously examined (Leal-Morales $e t$ al., 1988 ), and $\mathrm{D} 3 \mathrm{C}$ (MAT $\alpha$ ura3-52), a strain arising from the same tetrad in the above gene disruption (Bulawa et al., 1986; Sburlati \& Cabib, 1986). The D3B and D3C strains were kindly provided by E. Cabib (NIH, Bethesda, MD 20892, USA).

Culture conditions. Strain ATCC 26109 was cultivated in two liquid media: (i) a filter-sterilized medium containing $0.7 \%$ $(\mathrm{w} / \mathrm{v})$ yeast nitrogen base (Difco) and $2 \%(\mathrm{w} / \mathrm{v})$ glucose (YNBG), and (ii) a YPG medium containing $1 \%(\mathrm{w} / \mathrm{v})$ yeast extract, $2 \%(\mathrm{w} / \mathrm{v})$ peptone, and $2 \%(\mathrm{w} / \mathrm{v})$ glucose. Media were autoclaved at $121^{\circ} \mathrm{C}$ for $15 \mathrm{~min}$. Strains D3C and D3B were grown only on YPG medium because they were auxotrophic. Cultures were grown at $30^{\circ} \mathrm{C}$ in a shaker bath at 150 r.p.m. Preinoculum $(25 \mathrm{ml})$ was started in the corresponding medium from a loopful of cells taken from a slant culture less than $15 \mathrm{~d}$ old. Approximately $12 \mathrm{~h}$ later, cells were transferred into fresh medium; usually $1200 \mathrm{ml}$ of either medium was used (initial density 250000 cells ml $\mathrm{m}^{-1}$ ). Cultures were grown for about $12 \mathrm{~h}$ and harvested in exponential phase at a cell density of $4-7 \times 10^{7}$ cells $\mathrm{ml}^{-1}$.

Preparation of cell-free extracts. Cells were collected by centrifugation at $1500 \mathrm{~g}$ for $5 \mathrm{~min}$, washed in $100 \mathrm{ml} 1 \mathrm{mM}$ EDTA, resuspended in $20 \mathrm{ml} 1 \mathrm{mM}$ EDTA, and filtered through a $5 \mu \mathrm{m}$ pore size Millipore nitrocellulose membrane. Suction was applied until all the liquid was drained. The cells were weighed (approx. 3.3-5.7 g) and placed into a $75 \mathrm{ml}$ Duran bottle; $2 \mathrm{ml}$ of glass beads $(0.45-0.50 \mathrm{~mm}$ diameter) and $1 \mathrm{ml}$ $17 \%(\mathrm{w} / \mathrm{v})$ sucrose in $1 \mathrm{mM}$ EDTA were added per $\mathrm{g}$ of wet cells. Cells were then distupted in a Braun MSK homogenizer for $12-15 \mathrm{~s}$ while the flask was cooled with $\mathrm{CO}_{2}$. After breakage, the crude extract was removed and the glass beads were washed with $1 \mathrm{mM}$ EDTA [ $1 \mathrm{ml}$ (g wet cells) $\left.{ }^{-1}\right]$. The crude extract and washings were combined and centrifuged at $1500 \mathrm{~g}$ for $10 \mathrm{~min}$. The supernatant was used for sucrose density gradient centrifugation.

Density gradient centrifugation. A 5-7 ml sample of the $1500 \mathrm{~g}$ supernatant was layered on top of a $33 \mathrm{ml}$ linear sucrose gradient $(10-65 \%, \mathrm{w} / \mathrm{v})$ in $50 \mathrm{mM}$ Tris/ $\mathrm{HCl}, \mathrm{pH} 7 \cdot 5$. Beckman Quick-Seal polyallomer ultracentrifuge tubes $(1 \mathrm{in.} \times 3.5 \mathrm{in}$.) were used. The tubes were centrifuged at $265000 \mathrm{~g}$ in a Beckman $70 \mathrm{Ti}$ rotor for $3 \mathrm{~h}$ or $20 \mathrm{~h}$. In some experiments the centrifugation was done under milder conditions at $75100 \mathrm{~g}$ in a Beckman SW-27 rotor. Where indicated, selected samples used for electron microscopy were further purified by isopycnic flotation (Lending et al., 1990). Pairs of adjacent gradient fractions were combined, and diluted with 2 vols $65 \%(\mathrm{w} / \mathrm{v})$ sucrose, to adjust the sucrose concentration to about $51-54 \%(\mathrm{w} / \mathrm{v})$. The samples were then applied to a $35 \mathrm{ml}$ linear sucrose gradient $(10-65 \%$, $\mathrm{w} / \mathrm{v}$ ) with a Pasteur pipette (inserted into the gradient at a depth with the same density as that of the sample), and centrifuged in a SW-27 rotor at $75100 \mathrm{~g}$ for $20 \mathrm{~h}$. All gradients were fractionated from the top with an ISCO fractionator; samples of $1 \mathrm{ml}$ were collected. All centrifugations were done at $4{ }^{\circ} \mathrm{C}$. Centrifugal forces are given as $r_{\mathrm{av}}$.

Enzyme assays. Chitin synthetase activity was measured as the incorporation of radioactivity from UDP- $\left[{ }^{14} \mathrm{C}\right] \mathrm{GlcNAc}$ into $5 \%(\mathrm{w} / \mathrm{v})$ TCA-insoluble material. The assay mixture contained $1 \mathrm{mM}$ UDP-GIcNAc (specific activity $31.4 \mathrm{mCi} \mathrm{mol}^{-1}$ ), $32 \mathrm{mM}$ GlcNAc and $4 \mathrm{mM} \mathrm{MgCl}$. Chs2 was assayed similarly, but $3 \mathrm{mM} \mathrm{Co}\left(\mathrm{NO}_{3}\right)_{2}$ was added instead of magnesium. Except where indicated, all assays for Chs1 or Chs2 were done in the presence of $80 \mu \mathrm{g}$ trypsin $\mathrm{ml}^{-1}$ to activate zymogenic chitin synthetase. One unit of enzyme is the amount that catalyses the incorporation of $1 \mathrm{nmol}$ GlcNAc $\mathrm{min}^{-1}$.

We determined 1,3- $\beta$-glucan synthetase activity by measuring the incorporation of radioactivity from UDP- $\left[{ }^{14} \mathrm{C}\right]$ Glc into $5 \%$ TCA-insoluble material, but the incubation was done in the presence of $5 \mathrm{mM} \mathrm{ATP}$ as described earlier (Leal-Morales $e t$ al., 1988; Leal-Morales \& Ruiz-Herrera, 1985). Enzyme activity is expressed in units. One unit is the amount of enzyme that catalyses the incorporation of $1 \mathrm{nmol}$ glucose $\mathrm{min}^{-1}$. Radioactivity was counted in an LS 3801 liquid scintillation spectrometer (Beckman).

Data processing. To obtain average enzyme profiles from replicated sucrose density gradients, the original data points in units of chitin synthetase or 1,3- $\beta$-glucan synthetase activity for each individual fraction were first converted to percentage of the total activity in the entire gradient and plotted against specific gravity. The resulting curves were digitized to generate ordinate values for 75 or 150 common specific gravity points with the aid of a Hewlett-Packard plotter model 7475 driven by the Graph PAD program, version 2.0 (Institute for Scientific Information). Mean values were calculated and plotted for each specific gravity.

To estimate the relative distribution of chitin synthetase on the sucrose gradients, the usual midway density point $\left(1.185 \mathrm{~g} \mathrm{ml}^{-1}\right)$ in the valley between the peaks of chitosomes and the peak of plasma membrane was regarded as the dividing line. Enzyme 
activity below this value was considered as chitosomal; activity above this point pertained to plasma membrane.

Staining for electron microscopy. Samples were negatively stained with $2.5 \%(\mathrm{w} / \mathrm{v})$ uranyl acetate as already described (Leal-Morales et al., 1988).

Specific gravity. This was calculated from the sucrose concentration values measured with an Abbe refractometer (Carl Zeiss).

Chemicals. Ultra-pure grade sucrose was from Schwarz/Mann Biotech. GlcNAc, UDP-GlcNAc and UDP-Glc were obtained from Sigma. UDP-[Glc- $\left.{ }^{14} \mathrm{C}\right] \mathrm{GlcNAc}\left(4-5 \mathrm{Ci} \mathrm{mol}^{-1}\right)$, UDP[Glc ${ }^{14} \mathrm{C}$ ]Glc $\left(240 \mathrm{Ci} \mathrm{mol}^{-1}\right)$ and Zymolyase-20T were purchased from ICN (Irvine, California, USA).

\section{RESULTS}

\section{Chs1 in wild-type strain ATCC 26109}

Growing cells. The chitin synthetase of this wild-type strain can be consistently separated into two major subcellular fractions, chitosomes and plasma membrane, by prolonged centrifugation $(20 \mathrm{~h})$ on sucrose density gradients $(265000 \mathrm{~g}$ in a $70 \mathrm{Ti}$ rotor; Fig. 1). Because of unavoidable minor variations in the profiles of chitin synthetase from one gradient to the next, we averaged the profiles from several separately centrifuged gradients to get a more reliable estimate of buoyant density and the relative distribution of the chitin synthetase populations (Fig. 1). Accordingly, after $20 \mathrm{~h}$ at $265000 \mathrm{~g}$, the chitosome fraction equilibrated at $1 \cdot 146-1 \cdot 150 \mathrm{~g} \mathrm{ml}^{-1}$, and the chitin synthetase associated with plasma membrane equilibrated at $1 \cdot 213-1 \cdot 214 \mathrm{~g} \mathrm{ml}^{-1}$ ('Table 1 ; Fig. 1 ). The culture medium affected the relative abundance of Chs1 in chitosomes and plasma membrane populations (see below).

Effect of culture medium. Because it was necessary to grow the auxotrophic mutant used for studies of Chs 2 in a richer culture medium than that used before to study Chs 1 in the wild-type strain ATCC 26109 (Leal-Morales et al., 1988), we compared the effect of the medium on the distribution of chitin synthetase in homogenates of this strain. The discrepant culture media did not affect the total amount of enzyme activity recovered in the gradients or the buoyant density of the two chitin synthetase fractions, but they did alter the relative proportions of chitosomal and plasma-membrane-bound chitin synthetase (Table 1 ; Fig. 1). In cells grown in rich medium (YPG), the chitosomal Chs1 was more abundant (range $59-80 \%$; mean $70 \%$ ) than plasma membrane Chs1 (range $20-41 \%$; mean $30 \%$ ). In cells grown in a poorer medium (YNBG) both populations were of similar abundance (Table 1).

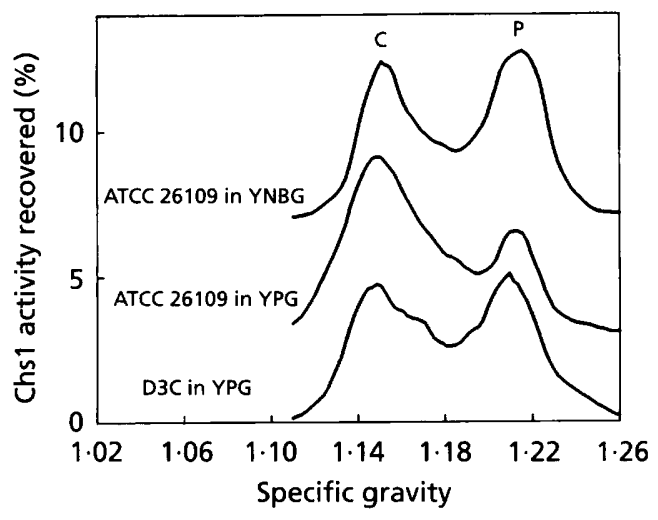

Fig. 1. Profiles of Chs 1 from S. cerevisiae wild-type strain ATCC 26109 and mutant strain D3C. The former was grown in two different culture media, YNBG and YPG. Cell-free extracts (5-7 ml; $1500 \mathrm{~g}$ supernatant) were applied to linear sucrose gradients and centrifuged for $20 \mathrm{~h}$ at $265000 \mathrm{~g}$. Each profile is the average of between three and seven individual runs. $C$, chitosome peaks; $\mathrm{P}$, plasma membrane peaks. Chs1 activity is expressed as a percentage of the total activity recovered in the gradient. To avoid overlapping, the upper two profiles were displaced vertically by 3 and $7 \%$, respectively.

\section{Table 1. Relative distribution of Chs 1 and Chs2 in sucrose density gradients}

Cell-free extracts ( $1500 \mathrm{~g}$ supernatants) from cells grown in either YPG or YNBG medium were centrifuged on sucrose gradients $(10-65 \%)$ for $20 \mathrm{~h}$ in either a $70 \mathrm{Ti}$ rotor $(265000 \mathrm{~g})$ or a SW-27 rotor $(75100 \mathrm{~g})$. Total enzyme present in the chitosomal

$\left(1.111 .185 \mathrm{~g} \mathrm{ml}^{-1}\right)$ and plasma membrane $\left(1.187-1.26 \mathrm{~g} \mathrm{ml}^{-1}\right)$ regions was averaged from several experiments and the relative abundance of chitin synthetase was calculated.

\begin{tabular}{|c|c|c|c|c|c|c|c|c|}
\hline \multirow[t]{2}{*}{ Enzyme } & \multirow[t]{2}{*}{ Strain } & \multirow{2}{*}{$\begin{array}{l}\text { Culture } \\
\text { medium }\end{array}$} & \multirow[t]{2}{*}{ Rotor } & \multirow{2}{*}{$\begin{array}{l}\text { No. of } \\
\text { runs }\end{array}$} & \multicolumn{2}{|c|}{ Chitosomes } & \multicolumn{2}{|c|}{ Plasma membrane } \\
\hline & & & & & $\begin{array}{c}\text { Relative } \\
\text { abundance } \\
(\%)\end{array}$ & $\begin{array}{c}\text { Peak } \\
\text { density } \\
\left(\mathrm{g} \mathrm{m}^{-1}\right)\end{array}$ & $\begin{array}{c}\text { Relative } \\
\text { abundance } \\
(\%)\end{array}$ & $\begin{array}{c}\text { Peak } \\
\text { density } \\
\left(\mathrm{g} \mathrm{ml}^{-1}\right)\end{array}$ \\
\hline \multirow[t]{4}{*}{ Chs1 } & ATCC 26109 & YPG & $70 \mathrm{Ti}$ & 6 & $69 \cdot 5$ & $1 \cdot 146$ & $30 \cdot 5$ & $1 \cdot 214$ \\
\hline & & YPG & SW-27 & 2 & $67 \cdot 9$ & $1 \cdot 150$ & $32 \cdot 1$ & $1 \cdot 190$ \\
\hline & & YNBG & $70 \mathrm{Ti}$ & 4 & $48 \cdot 4$ & $1 \cdot 150$ & $51 \cdot 6$ & $1 \cdot 213$ \\
\hline & $\mathrm{D} 3 \mathrm{C}$ & YPG & $70 \mathrm{Ti}$ & 3 & $53 \cdot 1$ & $1 \cdot 150$ & $46 \cdot 9$ & $1 \cdot 210$ \\
\hline \multirow[t]{2}{*}{ Chs2 } & D3B & YPG & $70 \mathrm{Ti}$ & 5 & $25 \cdot 0$ & NP & $75 \cdot 0$ & $1 \cdot 210$ \\
\hline & & YPG & SW-27 & 5 & $55 \cdot 9$ & $1 \cdot 165$ & $44 \cdot 1$ & $1 \cdot 205$ \\
\hline
\end{tabular}

${ }^{*} \mathrm{NI}^{\prime}$, No peak. 
Table 2. Recovery of Chs1 or Chs2 and 1,3- $\beta$-glucan synthetase activity in a prolonged centrifugation

Total enzyme units were measured in cell-free extracts from cells grown in YPG and centrifuged on sucrose density gradients at $265000 \mathrm{~g}$. The percentage of enzyme activity recovered after $20 \mathrm{~h}$ centrifugation is compared to that after $3 \mathrm{~h}$ centrifugation.

\begin{tabular}{|c|c|c|c|c|c|c|c|c|}
\hline \multirow[t]{3}{*}{ Enzyme } & \multirow[t]{3}{*}{ Strain } & \multicolumn{3}{|c|}{ Chitosomes } & \multicolumn{3}{|c|}{ Plasma membrane } & \multirow{3}{*}{$\begin{array}{c}\text { Total } \\
\text { recover } \\
(\%)\end{array}$} \\
\hline & & \multicolumn{2}{|c|}{$\begin{array}{c}\text { Total units } \\
\text { after } \\
\text { centrifugation } \\
\text { for: }\end{array}$} & \multirow[t]{2}{*}{$\begin{array}{c}\text { Recovery } \\
(\%)\end{array}$} & \multicolumn{2}{|c|}{$\begin{array}{c}\text { Total units } \\
\text { after } \\
\text { centrifugation } \\
\text { for: }\end{array}$} & \multirow[t]{2}{*}{$\begin{array}{c}\text { Recovery } \\
(\%)\end{array}$} & \\
\hline & & $3 \mathrm{~h}$ & $20 \mathrm{~h}$ & & $3 \mathrm{~h}$ & $20 \mathrm{~h}$ & & \\
\hline \multirow[t]{2}{*}{ Chs1 } & ATCC 26109 & $57 \cdot 8$ & $48 \cdot 5$ & 83.9 & $2 \div 6$ & $17 \cdot 4$ & $58 \cdot 8$ & $75 \cdot 4$ \\
\hline & $\mathrm{D} 3 \mathrm{C}$ & $67 \cdot 2$ & $52 \cdot 3$ & $77 \cdot 8$ & $4(1.9$ & $30 \cdot 8$ & $61 \cdot 7$ & $71 \cdot 0$ \\
\hline \multirow{4}{*}{$\begin{array}{l}\text { Chs2 } \\
1,3 \text { - } \beta \text {-Glucan } \\
\text { synthetase }\end{array}$} & D3B & $3 \cdot 4$ & $1 \cdot 4$ & $41 \cdot 2$ & $4 \cdot 0$ & $3 \cdot 3$ & $82 \cdot 5$ & 63.5 \\
\hline & ATCC 26109 & & & & $88 \cdot 0$ & $56 \cdot 6$ & $64 \cdot 3$ & \\
\hline & $\mathrm{D} 3 \mathrm{C}$ & & & & $27 \cdot 4$ & $37 \cdot 3$ & $136 \cdot 2$ & \\
\hline & D3B & & & & $2 \varepsilon \cdot 8$ & $27 \cdot 5$ & $95 \cdot 5$ & \\
\hline
\end{tabular}

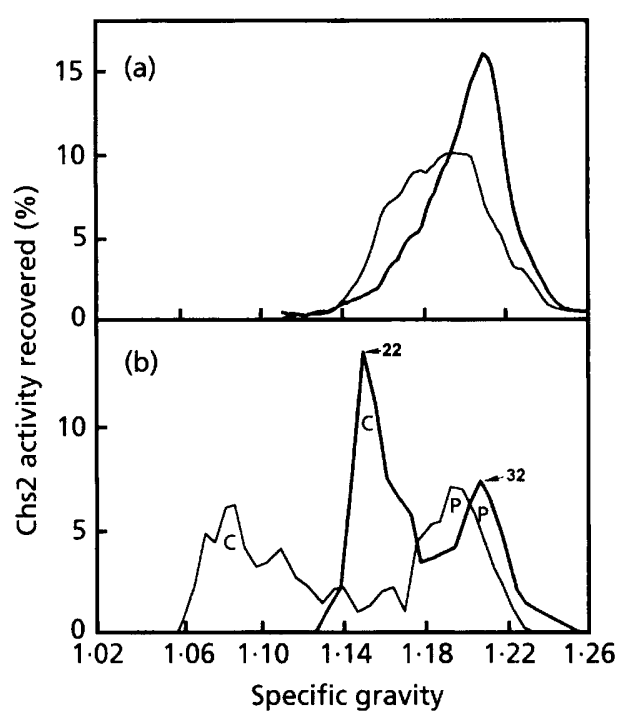

Fig. 2. Profiles of Chs2 from strain $D 3 B$ after (a) strong and (b) mild centrifugation. A 5-7 ml sample of cell-free extract $(1500 \mathrm{~g}$ supernatant) was applied on top of a sucrose gradient and centrifuged for $3 \mathrm{~h}$ (fine trace) or $20 \mathrm{~h}$ (heavy trace) in: (a) a $70 \mathrm{Ti}$ rotor at $265000 \mathrm{~g}$; (b) a SW-27 rotor at $75100 \mathrm{~g}$. Chs2 activity was assayed in the presence of $3 \mathrm{mM} \mathrm{Co}^{2+}$ and $80 \mu \mathrm{g}$ trypsin $\mathrm{ml}^{-1}$. In (a) each profile is the average of five individual runs. In (b) each profile corresponds to a single run. C, chitosome peak; $P$, plasma membrane peak. The positions of fractions 22 and 32 are indicated in (b).

\section{Chs1 in mutant strain D3C}

The Chs1 of strain D3C was compared with the Chs2 activity of its sister strain (D3B) used below. As with the Chs1 of ATCC 26109, two distinct peaks of chitin synthetase were cleanly resolved after a prolonged $20 \mathrm{~h}$ centrifugation (Fig. 1). Both chitin synthetase peaks from D3C had nearly identical buoyant densities to those from A TCC 26109 (Table 1). In this mutant strain, chitosomes and plasma membranes contained about equal amounts of the chitin synthetase recovered in the gradient. After a $20 \mathrm{~h}$ centrifugation, the overall recovery was $71 \%$ of the chitin synthetase activity present at $3 \mathrm{~h}$. Chitosomal and plasma membrane forms of Chs 1 of $\mathrm{D} 3 \mathrm{C}$ were about as stable as those from ATCC 26109 strain (Table 2).

\section{Chs2 in mutant strain D3B}

A homogenate of strain D3B (1500 $\boldsymbol{g}$ supernatant) was subjected to the same sucrose density gradient centrifugations used to separate Chs1 from wild-type cells $(265000 \mathrm{~g}$, for 3 or $20 \mathrm{~h}$ ). In contrast to Chs1, prolonged centrifugation at $265000 \boldsymbol{g}(20 \mathrm{~h})$ failed to reveal two populations of Chs2 (Fig. 2a); there was only one major peak of chitin synthetase in the plasma membrane region $\left(1.21 \mathrm{~g} \mathrm{ml}^{-1}\right)$ and little evidence of chitin synthetase activity in the chitosome region $\left(1.11-1.185 \mathrm{~g} \mathrm{ml}^{-1}\right)$. In a shorter centrifugation $(3 \mathrm{~h})$, a small amount of Chs 2 appeared in the chitosomal region (Fig. 2a; shoulder on the left of the main peak) but this was nearly wiped out upon continued centrifugation (Fig. 2a; Table 2).

Two possible explanations for the preferential loss of chitosomal Chs2 were considered: (i) the low-density activity (presumptive chitosomal enzyme) detected after $3 \mathrm{~h}$ was already at its equilibrium density but became unstable, or (ii) the low-density activity was not chitosomal but a denser form of chitin synthetase that had not yet reached equilibrium by $3 \mathrm{~h}$. To test these alternatives, a parallel sample of cell-free extract was centrifuged on a $10-65 \%$ sucrose gradient under milder conditions, a velocity sedimentation in a SW-27 rotor at $75100 \mathrm{~g}$. After $3 \mathrm{~h}$, two distinct chitin synthetase populations, a slow- 
Table 3. Properties of Chs 1 and Chs2 in two strains of S. cerevisiae: activation by trypsin, $\mathrm{Mg}^{2+}$ and $\mathrm{Co}^{2+}$

Crude extracts of strains made from the same amount of cells $\left(65 \times 10^{6}\right)$ of the ATCC 26109 and D3B strains were fractionated on a sucrose density gradient centrifuged for $20 \mathrm{~h}$ at $75100 \mathrm{~g}$. Chitin synthetase activity in the presence or absence of trypsin and $\mathrm{Mg}^{2+}$ or $\mathrm{Co}^{2}$ was measured in the fractions. The values shown are the sum of all individual fractions in the gradient.

\begin{tabular}{|c|c|c|c|c|c|}
\hline \multirow[t]{2}{*}{ Enzyme } & \multirow[t]{2}{*}{ Assay condition } & \multicolumn{4}{|c|}{ Chitin synthetase activity (units) } \\
\hline & & Chitosomal & Plasmalemma & Total & $\begin{array}{c}\text { Relative } \\
(\%)\end{array}$ \\
\hline \multirow{3}{*}{$\begin{array}{l}\text { Chs1 } \\
\text { (from wild-type strain } \\
\text { ATCC 26109) }\end{array}$} & Trypsin $\left(80 \mu \mathrm{g} \mathrm{ml}^{-1}\right)+\mathrm{Mg}^{2+}(4 \mathrm{mM})$ & $44 \cdot 1$ & $19 \cdot 5$ & $63 \cdot 6$ & 100 \\
\hline & Trypsin $\left(80 \mu \mathrm{g} \mathrm{ml}^{-1}\right)+\mathrm{Co}^{2+}(3 \mathrm{mM})$ & $9 \cdot 7$ & $3 \cdot 4$ & $13 \cdot 1$ & 21 \\
\hline & $\mathrm{Mg}^{2+}(4 \mathrm{mM})$ & $1 \cdot 1$ & $1 \cdot 1$ & $2 \cdot 2$ & 3 \\
\hline \multirow{3}{*}{$\begin{array}{l}\text { Chs } 2 \\
\text { (from mutant D3B) }\end{array}$} & Trypsin $\left(80 \mu \mathrm{g} \mathrm{ml}^{-1}\right)+\mathrm{Mg}^{2+}(4 \mathrm{mM})$ & $1 \cdot 7$ & $2 \cdot 1$ & $3 \cdot 8$ & 6 \\
\hline & Trypsin $\left(80 \mu \mathrm{g} \mathrm{ml}^{-1}\right)+\mathrm{Co}^{2+}(3 \mathrm{mM})$ & $5 \cdot 0$ & $4 \cdot 4$ & $9 \cdot 4$ & 15 \\
\hline & $\mathrm{Co}^{2+}(3 \mathrm{mM})$ & $2 \cdot 2$ & $2 \cdot 1$ & $4 \cdot 3$ & 7 \\
\hline
\end{tabular}

Table 4. Effect of centrifugal force on Chs2 activity from chitosomal and plasma membrane fractions of strain D3B

The chitosomal and plasma membrane populations separated from a cell-free extract of strain D3B on the SW-27 rotor centrifuged for $20 \mathrm{~h}$ at $75100 \mathrm{~g}$, were recentrifuged at two different centrifugal forces, $75100 \mathrm{~g}$ in the SW-27 rotor and $265000 \mathrm{~g}$ in the $70 \mathrm{Ti}$ rotor for $20 \mathrm{~h}$.

\begin{tabular}{|lccc|}
\hline Fraction & $\begin{array}{c}\text { Centrifugal } \\
\text { force } \\
(\boldsymbol{g})\end{array}$ & $\begin{array}{c}\text { Initial } \\
\text { activity } \\
\text { applied } \\
\text { (units) }\end{array}$ & $\begin{array}{c}\text { Activity } \\
\text { recovered } \\
\mathbf{( \% )}\end{array}$ \\
\hline Chitosome & 75100 & 0.56 & 70.6 \\
& 265000 & 0.56 & 38.9 \\
Plasma membrane & 75100 & 0.77 & 68.9 \\
& 265000 & 0.77 & 63.3 \\
\hline
\end{tabular}

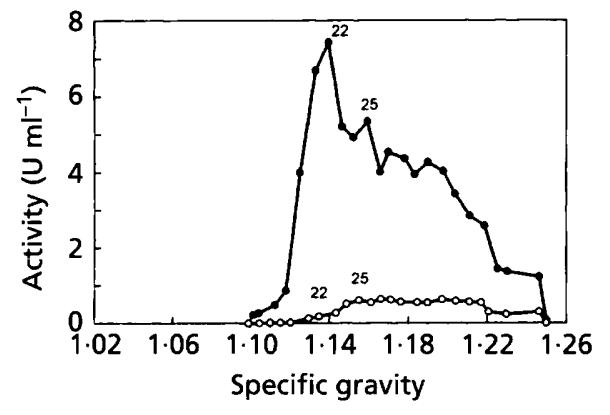

Fig. 3. Comparative activity of Chs1 and Chs2 from strain ATCC 26109 and mutant D3B, respectively. Samples of $1500 \mathrm{~g}$ supernatant, prepared from the same number of cells of each strain, were layered on sucrose density gradients and subjected to a mild centrifugation in the $5 W-27$ rotor at $75100 \mathrm{~g}$ for $20 \mathrm{~h}$. - Chs1: O, Chs2. The positions of fractions 22 and 25 are indicated (see Fig. 4). moving (chitosome) peak and a fast-moving (plasma membrane) peak, were detected (Fig. 2b). After $20 \mathrm{~h}$, the chitosome peak became compacted into a sharp peak at $d=1.149 \mathrm{~g} \mathrm{ml}^{-1}$, while the plasma membrane equilibrated at $1.207 \mathrm{~g} \mathrm{ml}^{-1}$. In general, the profiles of Chs2 were not as smooth as those of Chs1, but this is probably a result of experimental variation in view of the low levels of Chs 2 being measured. The buoyant density for the peaks of chitosomal Chs 2 oscillated in the range $1 \cdot 149-1 \cdot 175 \mathrm{~g} \mathrm{ml}^{-1}$ and $1 \cdot 195-1 \cdot 210 \mathrm{~g} \mathrm{ml}^{-1}$ for the plasma membrane. The chitosomal and plasma membrane populations comprised $56 \%$ and $44 \%$, respectively, of the Chs 2 activity recovered in the gradient (Fig. 2b; Table 1).

The detection of two populations of Chs 2 after prolonged centrifugation of cell-free extract in the swinging bucket (SW-27) rotor but not in the fixed angle (70Ti) rotor (Fig. $2 \mathrm{a}$ and $2 \mathrm{~b}$, respectively) led us to suspect that the stronger centrifugal force generated by the latter might have caused the selective destruction of the chitosomal population of Chs2. To compare the effect of different centrifugal forces (hydrostatic pressure), on chitin synthetase particles, we collected and pooled the suspected chitosome fractions (21-27) and plasma membrane fractions (28-34) from two identical gradients that had been centrifuged for $20 \mathrm{~h}$ at $75100 \mathrm{~g}$ (similar to the $20 \mathrm{~h}$ run in Fig. 2b). Duplicate samples of $5.7 \mathrm{ml}$ from the two pools were loaded into four (33 ml, 10-65\%) sucrose gradients. The samples were deposited with a Pasteur pipette inserted into the gradient at a depth with the same density as that of the sample. Each duplicate sample was centrifuged for $20 \mathrm{~h}$ under two different conditions: (i) SW-27 rotor at $75100 \mathrm{~g}$ and (ii) $70 \mathrm{Ti}$ rotor at $265000 \mathrm{~g}$. In both rotors, the recentrifuged samples equilibrated at the same densities as in the first centrifugation, approximately $1.17 \mathrm{~g} \mathrm{ml}^{-1}$ for chitosomes and $1.21 \mathrm{~g} \mathrm{ml}^{-1}$ for plasma membrane. In the SW-27 rotor there was no preferential destruction. Both the chitosomes and plasma membrane lost about $30 \%$ of activity during centrifugation (Table 4). However, in the $70 \mathrm{Ti}$ rotor, $61 \%$ of the activity of the 


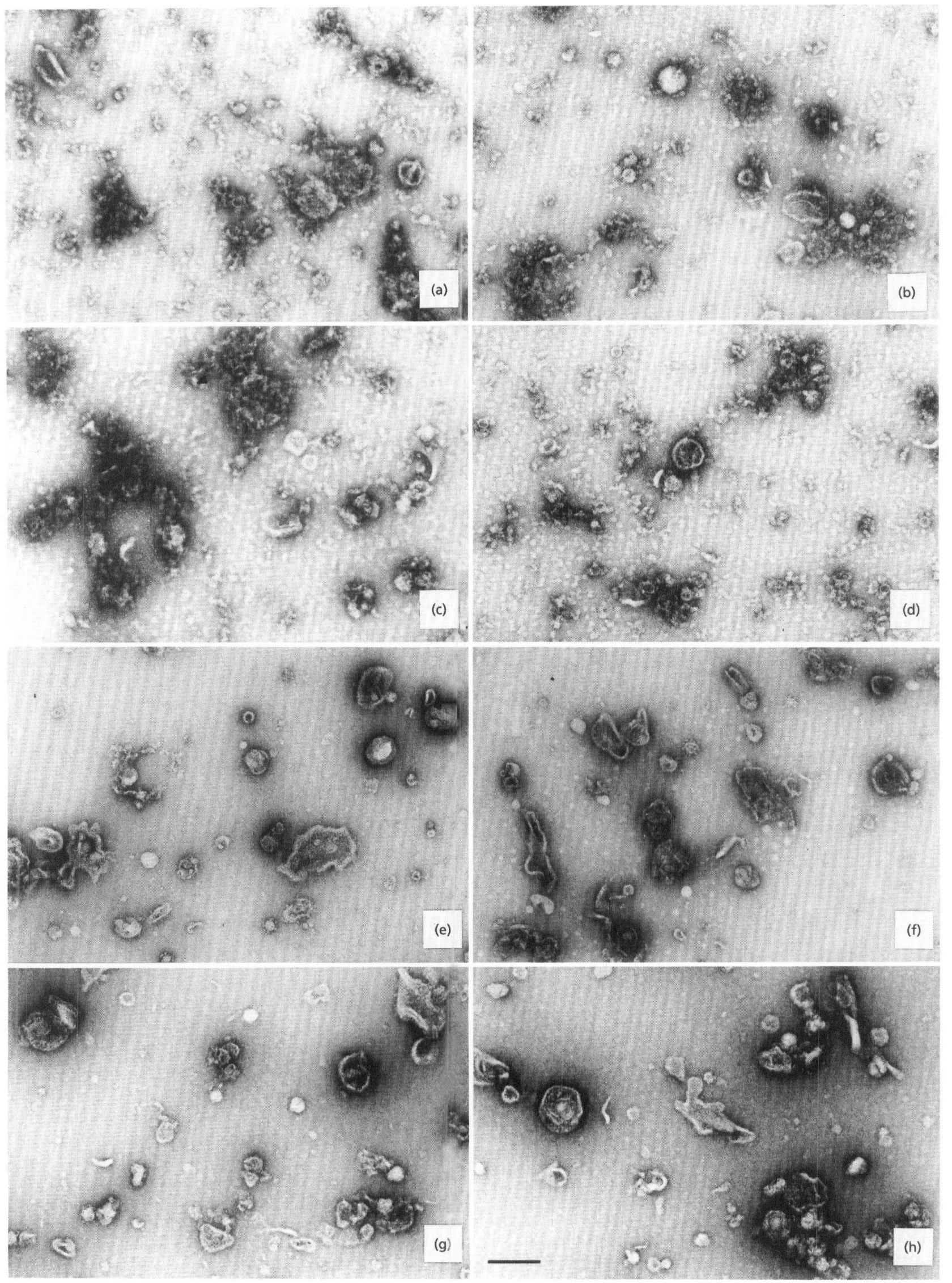


Table 5. Morphometry of vesicle populations from wildtype and mutant strain D3B of S. cerevisiae

A ninimum of 100 vesicles were measured from each of the samples shown in Fig. 4(e-h). Samples were from two places in the chitosome region: $d=1 \cdot 14$ and $d=1 \cdot 16$.

\begin{tabular}{|c|c|c|c|c|}
\hline \multirow{3}{*}{$\begin{array}{l}\text { Vesicle } \\
\text { diameter } \\
(\mathrm{nm})\end{array}$} & \multicolumn{4}{|c|}{$\begin{array}{l}\text { Relative abundance }(\%) \text { of vesicles } \\
\text { from strain: }\end{array}$} \\
\hline & \multicolumn{2}{|c|}{ ATCC 26109} & \multicolumn{2}{|c|}{ D3B } \\
\hline & $\begin{array}{l}d=1 \cdot 14 \\
\text { (Fig. 4e) }\end{array}$ & $\begin{array}{l}d=1 \cdot 16 \\
\text { (Fig. 4g) }\end{array}$ & $\begin{array}{l}d=1 \cdot 14 \\
\text { (Fig. 4f) }\end{array}$ & $\begin{array}{l}d=1 \cdot 16 \\
\text { (Fig. 4h) }\end{array}$ \\
\hline $40 \cdot 70$ & $37 \cdot 7$ & $27 \cdot 2$ & $32 \cdot 5$ & $29 \cdot 8$ \\
\hline 70) 100 & $64 \cdot 0$ & $47 \cdot 4$ & $58 \cdot 8$ & $53 \cdot 5$ \\
\hline 104$)-330$ & $36 \cdot 0$ & $52 \cdot 6$ & $41 \cdot 2$ & $46 \cdot 5$ \\
\hline $\begin{array}{l}\text { Median diameter } \\
(\mathrm{nm})\end{array}$ & $80 \cdot 7$ & $91 \cdot 7$ & 76.9 & $79 \cdot 3$ \\
\hline
\end{tabular}

chitosomal sample applied was lost after centrifugation at $265000 \mathrm{~g}$ for $20 \mathrm{~h}$; activity in the plasma membrane region was less affected by the centrifugal force, and only $37^{\circ} \%$ of the activity was lost.

To estimate the relative abundance of Chs1 and Chs2, we broke equal amounts of cells of the ATCC 26109 strain and the D3B mutant. The cell-free extracts were centrifuged at $71000 \mathrm{~g}$ for $20 \mathrm{~h}$ on sucrose density gradients. We found that the amount of Chs 2 recovered from the gradient was only $11-15 \%$ of the amount of Chs1 recovered from the wild-type strain (Table 3, Fig. 3).

\section{Electron microscopy}

To ascertain if the large quantitative differences in chitin synthetase activity between Chs1 and Chs 2 strains in the chitosome fractions reflected changes in abundance or morphology of particles, parallel samples from both gradients shown in Fig. 3 were compared. In both gradients, samples from two places in the chitosome region, at $d=1 \cdot 14$ (Fig. $4 \mathrm{a}, \mathrm{b}$ ) and at $d=1 \cdot 16$ (Fig. $4 \mathrm{c}, \mathrm{d}$ ) had a similar appearance: vesicles of widely different sizes were scattered among numerous smaller particles resembling ribosomes. To obtain a clearer view of vesicle size and distribution, selected samples were recentrifuged by isopycnic flotation. Most of the ribosomes and background contaminants disappeared, leaving a heterogeneous collection of vesicles (Fig. $4 \mathrm{e}-\mathrm{h}$, Table 5). There were no appreciable differences in vesicle abundance between the Chs1 strain (Fig. 4e, g) and the Chs2 strain (Fig. 4f, h). The median vesicle diameter was between $77-92 \mathrm{~nm}$; the proportion of microvesicles of typical chitosome size $(40-70 \mathrm{~nm})$ was similar $(27-37 \%)$ for the Chs 1 strain and the Chs 2 strain (Table 5). No attempt was made to separate the microvesicles from the larger vesicles as was done previously (Leal-Morales $e t$ al., 1988).

\section{Activators of chitin synthetase}

Chs2 required both trypsin and cobalt for maximum activity, and both the chitosomal and plasma membrane populations of Chs 2 behaved similarly in zymogenicity and metal requirement (Table 3). In contrast, Chs1 was better activated by magnesium than by cobalt. The activation by trypsin was much more pronounced for Chs1 than for Chs2: whereas Chs2 was activated 2-3-fold, Chs1 was increased 17-40-fold. From the values in Table 3 , it follows that nearly all of Chs1 $(97 \%)$ was zymogenic (only 2.2 out of 63.6 units were expressed in the absence of trypsin). For Chs $2,55 \%$ of the enzyme was zymogenic at the time of assay; the rest ( $4 \cdot 3$ out of $9 \cdot 4$ units) required no activation by trypsin.

\section{1,3- $\beta$-Glucan synthetase}

ATCC 26109. Two fractions of 1,3- $\beta$-glucan synthetase were detected in gradients from cells grown in YNBG medium (Fig. 5a). A major peak with a buoyant density of $1.220 \mathrm{~g} \mathrm{ml}^{-1}$ and $62.7 \%$ of the total activity was in the plasma membrane region. A somewhat smaller peak was found at a buoyant density of $1 \cdot 180 \mathrm{~g} \mathrm{ml}^{-1}$ (Table 6). The major peak of glucan synthetase coincided with the plasma membrane peak of chitin synthetase, but the minor peak did not (Fig. 5a, Tables 1, 6). In fact, there was practically no 1,3- $\beta$-glucan synthetase activity in the chitosome peak region $\left(1 \cdot 14-1.16 \mathrm{~g} \mathrm{ml}^{-1}\right)$. The profile of $1,3-\beta$-glucan synthetase was markedly affected by the culture medium. Thus, in cells grown on YPG, the profile of $1,3-\beta$-glucan synthetase was much more compact and the peaks were closer together (Fig. 5b, Table 6).

Mutant D3C. After $20 \mathrm{~h}$ centrifugation at $265000 \mathrm{~g}$, most of the $1,3 \beta$-glucan synthetase present in this strain appeared as a single broad peak with a density of

Fig. 4. Comparative morphology of parallel cell fractions containing Chs1 and Chs2 from S. cerevisiae strains ATCC 26109 $(a, c, e, g)$ and mutant D3B $(b, d, f, h)$, respectively. Parallel fractions from the gradients in Fig. 3 were examined before $(a, b, c, d)$ and after $(e, f, g, h)$ an additional centrifugation (isopycnic flotation) at $75100 \mathrm{~g}$ for $20 \mathrm{~h}$. Fractions were selected from two different densities in the gradients: $d=1.14(a, b, e, f)$ and $d=1.16(c, d, g, h)$. The initial samples (a, $b, c, d)$ were taken from the gradients in Fig. 3 as follows: (a) ATCC 26109 sample at $d=1 \cdot 14$ (combined fractions $21+22$ ); (b) D3B sample at $d=1 \cdot 14$ (combined fractions $22+23$ ); (c) ATCC 26109 sample at $d=1 \cdot 16$ (combined fractions $25+26$ ); (d) D3B sample at $d=1 \cdot 16$ (combined fractions $25+26$ ). For isopycnic flotation, samples $a, b, c$, and $d$ were each independently mixed with two volumes of $65 \%$ sucrose, introduced near the bottom of linear $10-65 \%$ sucrose density gradients, and recentrifuged at $75100 \mathrm{~g}$ for $20 \mathrm{~h}$. Samples from the four gradients were withdrawn at densities corresponding to those in the original samples and examined microscopically: $d=1.14(\mathrm{e}, \mathrm{f})$ and $d=1.16(\mathrm{~g}, \mathrm{~h})$. Bar, $100 \mathrm{~nm}$. 


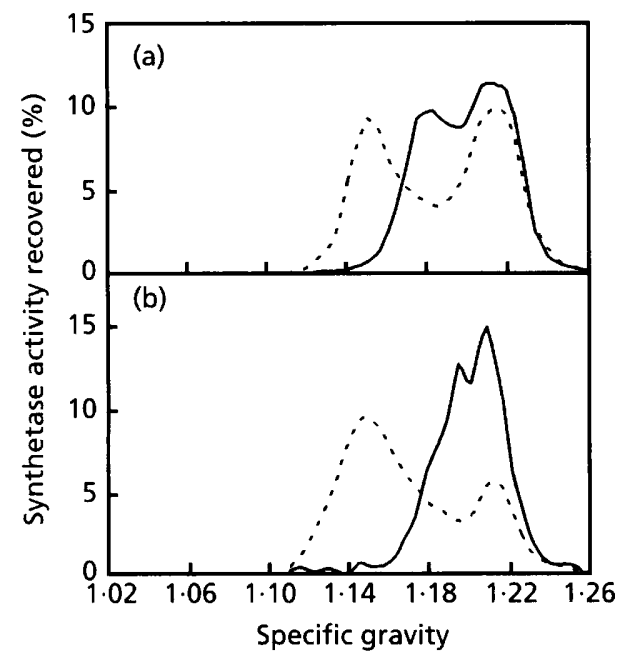

Fig. 5. Distribution of 1,3- $\beta$-glucan synthetase activity from the wild-type strain ATCC 26109 grown in two different culture media: (a) YNBG medium, (b) YPG medium. The cell-free extracts were processed as described for Fig. 1, and centrifuged for $20 \mathrm{~h}$ at $265000 \mathrm{~g}$. Average 1,3- $\beta$-glucan synthetase profiles $(\longrightarrow)$ are compared with the average chitin synthetase profiles $(--)$ from Fig. 1.

$1.208 \mathrm{~g} \mathrm{ml}^{-1}$. This peak co-sedimented with the plasma membrane peak of chitin synthetase (Tables 1,6). A shoulder of $1,3-\beta$-glucan synthetase was at ca $1 \cdot 180 \mathrm{~g} \mathrm{ml}^{-1}$ (Fig. 6). The enzyme profiles of this mutant resembled those of the wild-type strain ATCC 26109 (Fig. 6).

Mutant D3B. As with strain D3C, most of $1,3-\beta$-glucan synthetase present in the cell-free extract $(1500 \mathrm{~g}$ supernatant) of sister strain D3B appeared in a single broad peak with a density of $1.205 \mathrm{~g} \mathrm{ml}^{-1}$ after $20 \mathrm{~h}$ centrifugation at $265000 \mathrm{~g}$ (Table 6 ). This $1,3-\beta$-glucan synthetase co-sedimented with the plasma membrane peak of chitin synthetase (Tables 1, 6), including a shoulder at approximately $1 \cdot 180 \mathrm{~g} \mathrm{ml}^{-1}$ as with the other strains (Fig. 6).

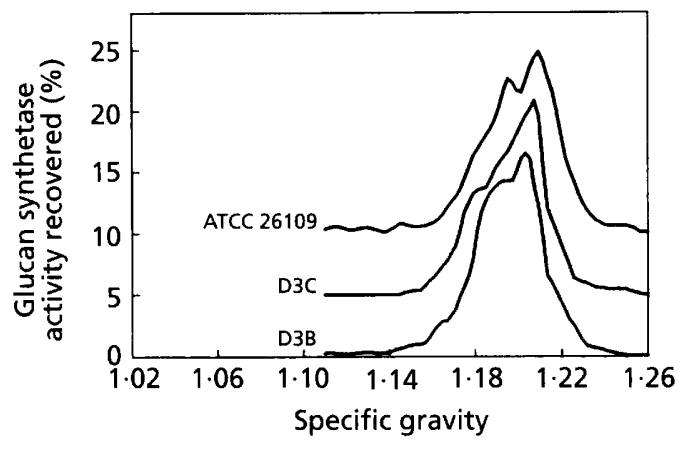

Fig. 6. Profiles of 1,3- $\beta$-glucan synthetase from homogenates of the ATCC 26109 and the two sister strains, D3C and D3B, of $S$. cerevisiae grown on YPG medium. The profiles were obtained after a $20 \mathrm{~h}$ centrifugation as described for Fig. 1. To avoid overlapping, the profiles of D3C and ATCC 26109 were displaced vertically by 5 and $10 \%$, respectively.

\section{DISCUSSION}

\section{Subcellular localization of Chs1 and Chs2}

We found that Chs 2 occurs in the same two vesicle populations that were previously identified for Chs1 in $S$. cerevisiae (Leal-Morales et al., 1988): (i) chitosomes, microvesicles (diameter typically $40-70 \mathrm{~nm}$ ) with a low buoyant density $\left(1 \cdot 15 \mathrm{~g} \mathrm{ml}^{-1}\right)$, lacking $1,3-\beta$-glucan synthetase activity; and (ii) plasma membrane vesicles of larger diameter (>100 nm), higher buoyant density $\left(1 \cdot 21 \mathrm{~g} \mathrm{ml}^{-1}\right)$, and rich in 1,3- $\beta$-glucan synthetase.

In our previous work on Chs1 (Leal-Morales et al., 1988), we emphasized that an appropriate centrifugation protocol was the key to successful fractionation of different vesicle populations from cell-free extracts on sucrose density gradients. Thus, to isolate a relatively pure sample of chitosomes from S. cerevisiae two steps were required: a prolonged, strong, isopycnic centrifugation $(20 \mathrm{~h}$ at $265000 \mathrm{~g})$ to separate chitosomes from the plasma-membrane-bound enzyme, and a velocity sedimentation to segregate the chitosome microvesicles from

\section{Table 6. Relative distribution of 1,3- $\beta$-glucan synthetase in sucrose density gradients}

Cell-free extracts ( $1500 \mathrm{~g}$ supernatants) from cells grown in either J'PG or YNBG medium were centrifuged on sucrose gradients $(10-65 \%$ ) at $265000 \mathrm{~g}$ in the $70 \mathrm{Ti}$ rotor for $20 \mathrm{~h}$. Total enzyme values were calculated for two regions of the gradient. Values from several experiments were averaged and the relative abundance of $1,3-\beta$-glucan synthetase was calculated.

\begin{tabular}{|c|c|c|c|c|c|c|}
\hline \multirow[t]{2}{*}{ Strain } & \multirow{2}{*}{$\begin{array}{l}\text { Culture } \\
\text { medium }\end{array}$} & \multirow{2}{*}{$\begin{array}{l}\text { No. of } \\
\text { runs }\end{array}$} & \multicolumn{2}{|c|}{ Minor peak } & \multicolumn{2}{|c|}{ Major peak } \\
\hline & & & $\begin{array}{c}\text { Relative } \\
\text { abundance } \\
(\%)\end{array}$ & $\begin{array}{c}\text { Peak } \\
\text { density } \\
\left(\mathrm{g} \mathrm{ml}^{-1}\right)\end{array}$ & $\begin{array}{c}\text { Relative } \\
\text { abundance } \\
(\%)\end{array}$ & $\begin{array}{c}\text { Peak } \\
\text { density } \\
\left(\mathrm{g} \mathrm{ml}^{-1}\right)\end{array}$ \\
\hline \multirow[t]{2}{*}{ ATCC 26109} & YPG & 3 & $32 \cdot 2$ & $1 \cdot 195$ & $67 \cdot 8$ & $1 \cdot 218$ \\
\hline & YNBG & 3 & $37 \cdot 3$ & $1 \cdot 180$ & $62 \cdot 7$ & $1 \cdot 220$ \\
\hline $\mathrm{D} 3 \mathrm{C}$ & YPG & 1 & $37 \cdot 7$ & $1 \cdot 180$ & $62 \cdot 3$ & $1 \cdot 208$ \\
\hline D3B & YPG & 2 & $42 \cdot 0$ & $1 \cdot 180$ & $58 \cdot 0$ & $1 \cdot 205$ \\
\hline
\end{tabular}


larger vesicles of equal density. Such an elaborate protocol for separation of vesicles containing Chs 2 was not feasible because of the small amounts of Chs 2 present in the cell plus the lack of stability of chitosomal Chs2 during highspeed centrifugation.

\section{Differences between Chs1 and Chs2}

We confirmed that Chs2 is present in yeast cells in much lower proportions than Chs1 $(11-15 \%)$. Our procedure probably enabled greater recovery of Chs 2 activity than the procedure used by Sburlati \& Cabib (1986), who reported a Chs 2 content of $5 \%$. We also confirmed that Chs2 is preferentially stimulated by $\mathrm{Co}^{2+}$ rather than by $\mathrm{Mg}^{2+}$ (Sburlati \& Cabib, 1986). We also found, as did the latter authors, that Chs2 is a zymogen which can be activated by trypsin, although Chs 2 zymogen is activated much less than Chs1. We interpret this reduced zymogenicity of Chs 2 as an indication that the smaller pool of chitin synthetase is more prone to undergo spontaneous activation by endogenous proteases in the cell-free extract.

Orlean (1987) found that Chs2 was not activated by trypsin. However, Shaw et al. (1991) believed that the enzyme studied by Orlean was actually Chs3, which according to Bulawa \& Osmond (1990) does not respond to protease activation.

Our values for Chs 2 may include some Chs 3 activity since the latter is also present in the D3B mutant. However, given that the total amount of Chs 3 detectable in cell-free extracts is much smaller than that of Chs2, and that our assavs were done under conditions that favoured Chs2 ( $\mathrm{Co}^{2+}$ rather than $\mathrm{Mg}^{2+}$ as a cofactor) and destroyed Chs3 (trypsin treatment), we conclude that only a small percentage of the total activity detected in the D3B mutant may be ascribed to Chs3. A novel difference between Chs 1 and Chs 2 was the relative instability of chitosomal Chs 2 during high-speed centrifugation.

\section{Destruction of Chs2 by hydrostatic pressure}

The destruction of Chs 2 during long centrifugation at $265000 \mathrm{~g}$ was unexpected. Previous studies with the Chs1 of $S$. cerevisiae had shown no such destruction of chitosomal chitin synthetase during prolonged high speed centrifugation. Similarly, the chitin synthetase in chitosomes from Mucor rouxii (Flores-Martinez et al., 1990; Kamada et al., 1991) exposed to even higher forces $\left(373000 \mathrm{~g}, r_{\mathrm{av}}\right)$ survived with no apparent destruction. Since the Chs 1 and Chs 2 of $S$. cerevisiae are equally stable at $1 \mathrm{~g}$ (non-centrifuged samples), the selective loss of activity of Chs 2 during high-speed centrifugation must have been caused by the enormous hydrostatic pressure exerted by the high centrifugal force. At the place in the gradient where chitosomes equilibrate, the pressure was at 460 and $1000 \mathrm{~atm}$ at 75100 and $265000 \mathrm{~g}$, respectively.

There are a number of reports on the deleterious effect of hydrostatic pressure on enzymes. Champeil et al. (1981) found that high pressure during high-speed centrifugation irreversibly inactivated the ATPase of sarcoplasmic reticulum vesicles. High pressure rendered fish lactate dehydrogenase more susceptible to proteolytic degradation (Hennessey \& Siebenaller, 1987) and caused the reversible inactivation of bacterial tryptophan synthetase (Seifert et al., 1984) and mitochondrial ATPase synthase (Dreyfus et al., 1988). Since plasma-membrane-bound Chs 2 was much more stable than the chitosomal Chs2, the instability may not be caused solely by the structural changes in the Chs 2 molecule but by other factors present in the chitosomes of the D3B strain that may render Chs2 more susceptible to degradation. We ruled out the possibility that the selective destruction of Chs 2 was caused by a soluble protease that moved into the chitosome band during protracted centrifugation as occurred when chitosomes of $M$. rouxii were isolated by high-speed centrifugation (Kamada et al., 1991).

\section{Changes induced by the culture medium}

Although the relative abundance of the two vesicle populations of Chs1 was affected by culture conditions, the buoyant density, a gross indicator of composition, remained the same. In contrast, the same changes in culture medium affected the buoyant density of the 1,3- $\beta$ glucan synthetase peaks. This discrepant behaviour suggests that these two polysaccharide synthetases may be contained in different vesicle subpopulations.

\section{Conclusion}

This study showed that Chs1 and Chs2 are located in the same subcellular sites despite structural (genetic) differences that affect other properties of these enzymes. We confirmed that chitin synthetase and 1,3- $\beta$-glucan synthetase, two enzymes that function at the cell surface, exhibit different subcellular distributions in fractionated homogenates. This is a strong indication that these two wall-synthesizing enzymes are mobilized to the cell surface through different secretory pathways.

\section{ACKNOWLEDGEMENTS}

This work was supported in part by grants from the National Institutes of Health, USA (GM-33513) and the National Science Foundation, USA (INT-8413728). Journal Paper no. 13858 of the Purdue University Agricultural Experiment Station. We thank E. Cabib for donating strains of $S$. cerevisiae D3B and D3C for this study.

\section{REFERENCES}

Bartnicki-Garcia, S., Bracker, C. E., Reyes, E. \& Ruiz-Herrera, J. (1978). Isolation of chitosomes from taxonomically diverse fungi and synthesis of chitin microfibrils in vitro. Exp Mycol 2, 173-192.

Bowen, A. R., Chen-Wu, J. L., Momany, M., Young, R., Szaniszlo, P. J. \& Robbins, P. W. (1992). Classification of fungal chitin synthases. Proc Natl Acad Sci USA 89, 519-523.

Bracker, C. E., Ruiz-Herrera, J. \& Bartnicki-Garcia, S. (1976). Structure and transformation of chitin synthetase particles (chitosomes) during microfibril synthesis in vitro. Proc Natl Acad Sci US A 73, 4570-4574.

Bulawa, C. E. (1993). Genetics and molecular biology of chitin synthesis in fungi. Annu Rev Microbiol 47, 505-534. 
Bulawa, C. E. \& Osmond, B. C. (1990). Chitin synthase I and chitin synthase II are not required for chitin synthesis in vivo in Saccharomyces cerevisiae. Proc Natl Acad Sci US A 87, 7424-7428.

Bulawa, C. E., Slater, M., Cabib, E., Au-Young, J., Sburlati, A., Adair, W. L. \& Robbins, P. W. (1986). The $S$. cerevisiae structural gene for chitin synthase is not required for chitin synthesis in vivo. Cell 46, 213-225.

Cabib, E. \& Farkas, V. (1971). The control of morphogenesis: An enzymatic mechanism for the initiation of septum formation in yeast. Proc Natl Acad Sci USA 68, 2052-2056.

Cabib, E., Bowers, B. \& Roberts, R. L. (1983). Vectorial synthesis of a polysaccharide by isolated plasma membranes. Proc Natl Acad Sci US A 80, 3318-3321.

Cabib, E., Sburlati, A., Bowers, B. \& Silverman, S. J. (1989). Chitin synthase 1 , an auxiliary enzyme for chitin synthesis in Saccharomyces cerevisiae. J Cell Biol 108, 1665-1672.

Champeil, P., Büschlen, S. \& Guillain, F. (1981). Pressure-induced inactivation of sarcoplasmic reticulum adenosine triphosphatase during high-speed centrifugation. Biochemistry 20, 1520-1524.

Dalley, N. E. \& Sonneborn, D. R. (1982). Evidence that Blastocladiella emersonii zoospore chitin synthetase is located at the plasma membrane. Biochim Biophys Acta 686, 65-76.

Dreyfus, G., Guimaraes-Motta, H. \& Silva, J. L. (1988). Effect of hydrostatic pressure on the mitochondrial ATP synthase. Biochemistry 27, 6704-6710.

Duran, A., Bowers, B. \& Cabib, E. (1975). Chitin synthetase zymogen is attached to the yeast plasma membrane. Proc Natl Acad Sci US A 72, 3952-3955.

Flores Martinez, A. \& Schwencke, J. (1988). Chitin synthetase activity is bound to chitosomes and to the plasma membrane in protoplasts of Saccharomyces cerevisiae. Biocbim Biophys Acta 946, 328-336.

Flores Martinez, A., Lopez-Romero, E., Martinez, J. P., Bracker, C. E., Ruiz-Herrera, J. \& Bartnicki-Garcia, S. (1990). Protein composition of purified chitosomes from Mucor rouxii. Exp Mycol $14,160-168$.

Gozalbo, D., Dubon, F. \& Sentandreu, R. (1992). Chitin synthetase activity is bound to the plasma membrane and to a cytoplasmic particulate fraction in Candida albicans germ tube cells. FEMS Microbiol Lett 97, 255-260.
Hanseler, E., Nyhlen, L. E. \& Rast, D. M. (1983). Isolation and properties of chitin synthetase from Agaricus bisporus mycelium. Exp Mycol 7, 17-30.

Hennessey, J. P. \& Siebenaller, J. F. (1987). Inactivation of NADdependent dehydrogenases from shallow- and deep-living fishes by hydrostatic pressure and proteolysis. Biochim Biophys Acta 913, 285-291.

Jan, Y. N. (1974). Properties and cellular localization of chitin synthetase in Phycomyces blakesleeanus. J Biol Chem 249, 1973-1979.

Kamada, T., Bracker, C. E., Lippman, E. \& Bartnicki-Garcia, S. (1991). Unexpected destruction of chitosomal chitin synthetase by an endogenous protease during sucrose density gradient purification. J Cell Sci 99, 565-570.

Leal-Morales, C. A. \& Ruiz-Herrera, J. (1985). Alterations in the biosynthesis of chitin and glucan in the slime mutant of Neurospara crassa. Exp Mycol 9, 28-38.

Leal-Morales, C. A., Bracker, C. E. \& Bartnicki-Garcia, S. (1988). Localization of chitin synthetase in cell-free homogenates of Saccharomyces cerevisiae: chitosomes and plasma membrane. Proc Natl Acad Sci US A 85, 8516-8520.

Lending, C. R., Lippman, E., Bracker, C. E. \& Bartnicki-Garcia, S. (1990). An efficient preparative isopycnic flotation method for the isolation of chitosomes. Protoplasma 159, 16-25.

Orlean, P. (1987). Two chitin synthases in Saccharomyces cerevisiae. I Biol Chem 262, 5732-5739.

Sburlati, A. \& Cabib, E. (1986). Chitin synthetase 2, a presumptive participant in septum formation in Saccharomyces cerevisiae. J Biol Chem 261, 15147-15152.

Seifert, T., Bartholmes, P. \& Jaenicke, R. (1984). High-pressure dissociation of the $\beta_{2}$-dimer of tryprophan synthase from Eschericbia coli monitored by sucrose density centrifugation. FEBS Lett 173 , 381-384.

Shaw, J. A., Mol, P. C., Bowers, B., Silverman, S. J., Valdivieso, M. H., Duran, A. \& Cabib, E. (1991). The function of chitin synthases 2 and 3 in the Saccharomyces cerevisiae cell cycle. J Cell Biol 114, 111-123.

Silverman, S. J., Sburlati, A., Slater, M. L. \& Cabib, E. (1988). Chitin synthase 2 is essential for septum formation and cell division in Saccharomyces cerevisiae. Proc Natl Acad Sci US A 85, 4735-4739.

Received 4 March 1994; accepted 12 April 1994. 